\title{
Antidepressant Effects of Standardized Extract of Commiphora mukul Engl. in Olfactory Bulbectomized Rats
}

\author{
Padmaja Bhimashankar Kalshetti ${ }^{1}$, Ramesh Alluri ${ }^{2}$ and Prasad Arvind Thakurdesai ${ }^{3^{*}}$ \\ ${ }^{1}$ Department of Pharmacology; MAEER'S Maharashtra Institute of Pharmacy; Kothrud, Pune - India. ${ }^{2}$ Department \\ of Pharmacology; Vishnu Institute of Pharmaceutical Education and Research; Narsapur, Andhra Pradesh - India. \\ ${ }^{3}$ Department of Scientific affairs; Indus Biotech Private Limited; Kondhwa, Pune - India
}

\begin{abstract}
The objective of this work was to evaluate the effects of standardized hydroalcholic extract of Commiphora mukul (HECM) in animal model of chronic stress medicated depression, namely olfactory bulbectomy (OBX) model in rats. Effects of 14-day (subacute) oral pretreatment of HECM (50, 100 and $200 \mathrm{mg} / \mathrm{kg}$ ) were evaluated on depression and stress related parameters on OBX rats. Separate groups for sham control, OBX control and positive controls namely imipramine $(20 \mathrm{mg} / \mathrm{kg})$, fluoxetine $(30 \mathrm{mg} / \mathrm{kg})$ and desipramine $(15 \mathrm{mg} / \mathrm{kg})$ were also maintained. Behavioral and physiological parameters in open field and elevated plus maze were recorded. HECM showed dose-dependent reversal of OBX-induced physiological effects such as reduction of body weight, body temperature, heart rate and serum sodium concentration. HECM also showed reversal effects on OBX induced food intake increase and hyperactivity in open field and elevated plus maze paradigm. In conclusion, HECM demonstrated restorative effects in OBX induced depression model in rats probably due to stress reliving mechanisms.
\end{abstract}

Key words: Antidepressant Activity, Commiphora Mukul Engl, Guggul, Olfactory Bulbectomy Model

\section{INTRODUCTION}

Depression is a chronic, recurring and potentially life-threatening illness that affects up to $17 \%$ of the population across the globe (Freitas et al. 2013). Depressive symptoms include somatic as well as cognitive alterations such as anhedonia (Moreau 2002), depressed mood, irritability, worthlessness or guilt, feelings of hopelessness, decreased ability to concentrate and think, decreased or increased appetite, weight loss or weight gain (Cole et al. 2012), insomnia or hypersomnia, fatigue, psychomotor retardation or agitation, low energy and recurrent thoughts of death and suicide (Hirsch et al. 2011). Although the current pharmacotherapy of depression includes a battery of drugs, many are inconsistently effective and exert undesirable side effects (Morilak and Frazer 2004). Therefore, considerable efforts are invested in the development of alternative therapeutic approaches for the management of depressive disorders.

Commiphora mukul Engl (Hook. ex Stocks) is a small tree of the Burseraceae family that is found arid lands in India, northern Africa and central Asia (Siddiqui 2011). The gum resin of the $C$. mukul tree, its resinous exudate sap known as gum (guggul) and gum extract (called gugulipid, guggulipid or guglipid) are described in the traditional literature of India such as Ayurveda and Unani systems for its medicinal properties (Siddiqui 2011). The gum resin of guggul is a very complex mixture of gum, minerals, essential oils, terpenes, sterols, ferrulates, flavanones and sterones. Guggulsterone (GS) [4,17(20)pregnadiene-3,16-dione] is a major phytosterol of $C$. mukul gum resin that exists in two stereoisomers: E-GS (cis-GS) and Z-GS (trans-

\footnotetext{
*Author for correspondence: prasad@indusbiotech.com
} 
GS) (Almazari et al. 2012). There is considerable scientific evidence showing gum guggul as a therapeutic agent (Shah et al. 2012). The ethanol extract of C. mukul gum resin is reported to have antidiabetic (Bellamkonda et al. 2011; Ramesh and Saralakumari 2012), antihyperlipedemic (Ramesh and Saralakumari 2012), antioxidant (Ramesh and Saralakumari 2012), and anti-bone resorptive (Khan et al. 2012) activities. The major phytosterol of C. mukul gum resin, GS, is also known for useful therapeutics properties (Shen et al. 2012; Pal et al. 2013).

Recently, many reports on $C$. mukul resin extract have indicated its stress reliving mechanism. For example, anti-fatigue effects represented by reduction in immobility duration has been reported in a rat study on sub-acute administration during forced swimming test (Hadipour et al. 2008). The role of serotoninergic system in mediation of satiety effects of OB-200G (a polyherbal preparation containing aqueous extracts of resin from $C$. mukul as a major ingredient) has been reported (Kaur and Kulkarni 2003). GS is reported to increase the levels of biogenic monoamines and decrease dopamine $\beta$ hydroxylase activity in rat tissues (Srivastava and Kapoor 1986). However, the stress reliving potential of $C$. mukul has not been yet explored towards management of depressive or mood disorders. The present study was an attempt to evaluate the potential of $C$. mukul extract in the animal model of depression (a stress related mood disorder).

The olfactory bulbectomy (OBX) is a wellestablished animal model for stress-induced depression (Leonard and Tuite 1981). OBX has been proposed as an animal model of depression in terms of constructive validity, since it induces alterations in behavior, and in the endocrine, immune and neurotransmitter systems that reproduces many of those seen in patients with clinical depression (Leonard and Tuite 1981; Kelly et al. 1996). Therefore, present work aimed to evaluate the HECM in olfactory bulbectomy (OBX)-induced depression in rats.

\section{MATERIAL AND METHODS}

\author{
Animals \\ Male Sprague Dawley rats (250-280 g) were \\ purchased from the National Toxicology Centre \\ (NTC), Pune. The animals were housed at $25 \pm$
}

$1^{\circ} \mathrm{C}$ and relative humidity of $45-55 \%$ under $12: 12 \mathrm{~h}$ light: dark cycle. At the time of housing, animals had free access to the feed pellets (Chakan Oil Mills Ltd., Sangli, and Maharashtra, India) and tap water ad libitum. The experimental protocol (No: MIP/IAEC/2013-14/M1/0012) was approved by the Institutional Animal Ethics Committee of Maharashtra Institute of Pharmacy, Pune, India. All observations were recorded between 8:00 and 15:00 $\mathrm{h}$ and each animal was used only once. To avoid the subjective bias, the observer was not aware about the given treatment (blind). Rats were transported from the animal house to the testing area in their own cages and were allowed to adapt to the new environment for $3 \mathrm{~h}$ before testing.

\section{Drugs and chemicals}

Imipramine hydrochloride, fluoxetine hydrochloride and desipramine were purchased from Sigma-Aldrich, USA. Ketamine and anaesthetic ether were purchased from Research Lab, Mumbai, India. The standardized extract of C. mukul (HECM) was purchased from Konark herbals, Mumbai, India.

\section{Bilateral OBX surgery in rats}

The depression-like symptoms in the rats were induced by bilateral OBX surgery according to reported procedure (Kalshetty et al. 2012). Briefly, the male Sprague Dawley rats were anaesthetized with ketamine $(80 \mathrm{mg} / \mathrm{kg}$ i.p.). The animal was placed in stereotaxic frame. Head was shaven and $1.0 \mathrm{~cm}$ midline scalp sagittal incision was made. Then bilateral $2.0 \mathrm{~mm}$ burr holes were drilled $8.0 \mathrm{~mm}$ anterior to bregma and $2.0 \mathrm{~mm}$ from the midline. Both, the main and accessory olfactory bulbs were aspirated through the both burr holes using a blunt hypodermic needle attached to suction pump without damaging the frontal cortex. The burr holes were then plugged with a hemostatic sponge to control the bleeding after the drilling. Povidone iodine solution was applied as an antiseptic to the wounds and allowed to recover for 14 days.

\section{Treatment schedule}

After 14 days from OBX, rats were divided into groups of six rats each and administered with drug treatments as follows: Group I was Sham control and was administered with saline in a dose of 1.0 $\mathrm{mL} / \mathrm{kg}$. Group II was OBX control rat without any treatment. Group III, IV and V were OBX rats and treated with imipramine $(20 \mathrm{mg} / \mathrm{kg} \quad$ p.o. $)$, 
fluoxetine (30 mg/kg, p.o.) and desipramine (15 $\mathrm{mg} / \mathrm{kg}$ p.o.), respectively. Groups VI, VII and VIII were treated with HECM (50, 100 and 200 $\mathrm{mg} / \mathrm{kg}$ ), respectively. All the treatments were given orally for 14 days.

\section{Effect on body weight and food intake in OBX rats}

The rats in all the groups were weighed before OBX and were placed individually in polypropylene cages. During the study period, the animal's body weight and food intake was measured $1 \mathrm{~h}$ before drug administration on day-1 (baseline), 7 and 14 after treatment to OBX rats.

\section{Effect on behavioral parameters during open field activity in OBX rats}

The behavioral effects were observed in open field test as reported earlier (Kelsch et al. 2012). The animals were placed in the center of open field apparatus and were observed for the period of 3 min for number of ambulation, rearing and grooming.

\section{Effect on physiological parameters and serum sodium in OBX rats}

The heart rate was measured at $30 \mathrm{~min}$ after open field activity. The rectal body temperature was measured at 5 min after open field activity with the help of telethermometer (Electrolab, India). The serum sodium concentration was measured using flame photometer (Systronic India Ltd, Model 128, Mumbai, India) following (Scott 1951).

\section{Effect on behavioral parameters in elevated plus maze in OBX rats}

The behavior in elevated plus maze was performed as reported earlier (Saitoh et al. 2007). Plus-Maze consisted of two open arms $50 \times 10 \times 40$ $\mathrm{cm}$ and two enclosed arms $50 \times 10 \times 40 \mathrm{~cm}$, with an open roof, arranged so that the two open arms were opposite to each other. The maze was elevated at the height of $50 \mathrm{~cm}$. The rats, which had undergone olfactory bulbectomy were tested in the elevated plus maze for anxiety. Thirty minutes after the administration of respective treatment, each rat was placed individually in the center of maze, facing one of the closed arms. During a 5-min test period, the following measurements were made: number of open arm entries, number of closed arm entries and time spent in open arm.

\section{Statistical analysis}

All data were expressed as mean \pm SEM. Results of food intake and body weight were analyzed by separate Two-way ANOVA followed by Bonferroni test. The data obtained for open field test elevated plus maze test and physiological parameters were analyzed by separate analysis for each parameter (One-way ANOVA followed by Dunnett's test).

\section{RESULTS}

\section{Effect on food intake and body weight}

As seen in Table 1, OBX rats showed significant increase in mean daily food intake $(\mathrm{P}<0.001)$ within $24 \mathrm{~h}$ (day 1) compared to sham control rats. This increase in mean daily food intake in OBX rats was sustained during the study period. Treatment with imipramine $(20 \mathrm{mg} / \mathrm{kg})$, fluoxetine $(30 \mathrm{mg} / \mathrm{kg})$, or desipramine $(15 \mathrm{mg} / \mathrm{kg})$ showed significant $(\mathrm{P}<0.001)$ reduction in food intake as compared with food intake by the OBX rats on day 7 and 14 of the study. HECM at all the doses significantly $(\mathrm{P}<0.001)$ reduced food intake as compared to food intake of the OBX rats of respective day.

As seen in Table 1, the mean body weight of the OBX control rats increased significantly $(\mathrm{P}<$ 0.001) compared to body weights of sham control rats of corresponding days. Treatment with imipramine $(20 \mathrm{mg} / \mathrm{kg})$, fluoxetine $(30 \mathrm{mg} / \mathrm{kg})$, or desipramine $(15 \mathrm{mg} / \mathrm{kg})$ as well as all the doses of HECM showed significant reduction in body weights as compared to the OBX animals of corresponding days.

\section{Effect on ambulation, rearing and grooming during open field test in the OBX rats}

The effects of behavioral parameters (ambulation, rearing and grooming) during open field test are presented in Table 2. OBX control rats showed significant $(\mathrm{P}<0.001)$ increase in ambulation (56.67\% increase) in the number of squares crossed as compared with sham control rats. Imipramine $(20 \mathrm{mg} / \mathrm{kg})$, Fluoxetine $(30 \mathrm{mg} / \mathrm{kg})$ and desipramine $(15 \mathrm{mg} / \mathrm{kg})$ treatment showed significant $(\mathrm{P}<0.001)$ reduction of the ambulation score $(52.33 \%, 35.56 \%$ and $54.9 \%)$, respectively compared to the OBX control rats. HECM $(50,100$ or $200 \mathrm{mg} / \mathrm{kg}$ ) reduced the ambulation scores significantly $(12.9,24.23$ and $35.11 \%$; $\mathrm{P}<0.001)$ compared to the OBX control rats. 
Table 1 - Effect of treatments on food intake and body weight in OBX rats.

\begin{tabular}{|c|c|c|c|c|c|c|}
\hline \multirow[t]{2}{*}{ Treatment } & \multicolumn{3}{|c|}{ Daily Food Intake in g/day (Mean \pm SEM) } & \multicolumn{3}{|c|}{ Daily body weight in g/day (Mean \pm SEM) } \\
\hline & Day 1 & Day 7 & Day 14 & Day 1 & Day 7 & Day 14 \\
\hline Sham control & $15.50 \pm 0.22$ & $19.66 \pm 0.88$ & $19.00 \pm 0.68$ & $262.33 \pm 13.56$ & $266.33 \pm 13.56$ & $279.66 \pm 14.77$ \\
\hline OBX control & $\begin{array}{c}24.45 \pm \\
0.89^{\# \# \#}\end{array}$ & $\begin{array}{c}26.90 \pm \\
0.90^{\# \# \#}\end{array}$ & $\begin{array}{l}26.25 \pm \\
0.44^{\# \# \#}\end{array}$ & $\begin{array}{l}315.00 \pm \\
11.63^{\# \# \#}\end{array}$ & $\begin{array}{c}316.33 \pm \\
11.07^{\# \# \#}\end{array}$ & $\begin{array}{l}322.66 \pm \\
11.41^{\# \# \#}\end{array}$ \\
\hline OBX + Imipramine & $11.35 \pm 1.01 * * *$ & $11.05 \pm 0.34 * * *$ & $12.30 \pm 0.38 * * *$ & $306.33 \pm 3.73$ & $282.50 \pm 7.80^{*}$ & $286.83 \pm 3.65^{* *}$ \\
\hline OBX + Fluoxetine & $13.95 \pm 0.26^{* * *}$ & $11.20 \pm 1.22 * * *$ & $09.45 \pm 1.61 * * *$ & $313.66 \pm 6.80$ & $280.50 \pm 7.48 * *$ & $275.00 \pm 7.37 * *$ \\
\hline OBX + Desipramine & $24.33 \pm 0.66$ & $19.83 \pm 0.44 * * *$ & $15.33 \pm 0.66^{* * *}$ & $305.83 \pm 10.07$ & $295.50 \pm 8.09$ & $286.00 \pm 10.78 * *$ \\
\hline OBX + HECM (50) & $22.16 \pm 0.57$ & $19.16 \pm 0.45^{* *}$ & $14.83 \pm 0.33 * *$ & $291.83 \pm 5.67$ & $273.16 \pm 5.19 * *$ & $261.83 \pm 5.68 * * *$ \\
\hline OBX + HECM (100) & $21.25 \pm 0.64$ & $17.16 \pm 0.91 * * *$ & $15.25 \pm 1.19 * * *$ & $293.66 \pm 3.35$ & $273.83 \pm 2.38^{* *}$ & $282.00 \pm 4.18 * *$ \\
\hline OBX + HECM (200) & $21.25 \pm 0.64$ & $17.16 \pm 0.91 * * *$ & $13.88 \pm 0.74 * * *$ & $293.66 \pm 3.35$ & $282.00 \pm 4.18^{*}$ & $275.83 \pm 4.36 * * *$ \\
\hline
\end{tabular}

Table 2 - Effect of treatments on behavioral and physiological parameters in the OBX rats.

\begin{tabular}{|c|c|c|c|c|c|c|}
\hline \multirow[t]{2}{*}{ Treatment } & \multicolumn{3}{|c|}{$\begin{array}{l}\text { Behaviour in open field test } \\
\text { (Mean Number } \pm \text { SEM) }\end{array}$} & \multicolumn{3}{|c|}{$\begin{array}{l}\text { Physiological parameters } \\
\text { (Mean Number } \pm \text { SEM) }\end{array}$} \\
\hline & Ambulation & Rearing & Grooming & $\begin{array}{c}\text { Heart } \\
\text { rate }(B P M)\end{array}$ & $\begin{array}{c}\text { Body Temp. } \\
\left({ }^{\circ} \mathrm{C}\right)\end{array}$ & $\begin{array}{l}\text { Serum Sodium } \\
(\mathrm{mEq} / \mathrm{L})\end{array}$ \\
\hline Sham control & $32.50 \pm 1.38$ & & & $359.3 \pm 3.55$ & $36.98 \pm 0.16$ & $13.79 \pm 1.00$ \\
\hline OBX control & $75.5 \pm 4.32^{\# \# \#}$ & $26.1 \pm 1.82^{\# \# \#}$ & $25.00 \pm 1.51^{\# \# \#}$ & $275.4 \pm 7.73^{\# \#}$ & $34.52 \pm 0.41^{\# \# \#}$ & $39.79 \pm 0.59^{\# \#}$ \\
\hline $\begin{array}{l}\text { OBX+ } \\
\text { Imipramine }\end{array}$ & $35.83 \pm 2.63 * * *$ & $13.8 \pm 1.67 * * *$ & $15.17 \pm 1.11 * * *$ & $437.5 \pm 7.89 * * *$ & $36.26 \pm 0.30 * * *$ & $32.98 \pm 3.08$ \\
\hline $\begin{array}{l}\text { OBX }+ \\
\text { Fluoxetine }\end{array}$ & $48.17 \pm 1.13 * * *$ & $15.00 \pm 0.83 * * *$ & $13.00 \pm 0.94 * * *$ & $376.8 \pm 5.64 * * *$ & $36.71 \pm 0.20 * * *$ & $23.38 \pm 0.48 * * *$ \\
\hline $\begin{array}{l}\text { OBX }+ \\
\text { Desipramine }\end{array}$ & $33.83 \pm 2.44 * * *$ & $12.50 \pm 0.81 * * *$ & $12.67 \pm 0.50 * * *$ & $414.5 \pm 14.72 * * *$ & $36.71 \pm 0.22 * * *$ & $31.68 \pm 2.50$ \\
\hline $\begin{array}{l}\text { OBX + } \\
\operatorname{HECM}(50)\end{array}$ & $65.33 \pm 2.21$ & $21.33 \pm 0.50 *$ & $19.33 \pm 2.10^{*}$ & $318.8 \pm 6.07 *$ & $36.54 \pm 0.34 * * *$ & $24.03 \pm 3.99 * * *$ \\
\hline $\begin{array}{l}\mathrm{OBX}+ \\
\mathrm{HECM}(100)\end{array}$ & $56.83 \pm 1.91 * * *$ & $18.00 \pm 0.58 * * *$ & $18.00 \pm 0.97 * *$ & $326.4 \pm 14.42 * *$ & $37.11 \pm 0.12 * * *$ & $25.50 \pm 3.21 * * *$ \\
\hline $\begin{array}{l}\text { OBX + HEC } \\
(200)\end{array}$ & $48.67 \pm 3.98 * * *$ & $16.50 \pm 0.43 * * *$ & $14.83 \pm 0.88 * * *$ & $339.8 \pm 11.40 * * *$ & $36.88 \pm 0.11 * * *$ & $14.50 \pm 1.10 * * *$ \\
\hline
\end{tabular}

The values are expressed as the mean \pm SEM. The treatments were administered once a day for 14 days. Figures in the bracket indicate dose in $\mathrm{mg} / \mathrm{kg}$, p.o. Data was analyzed by separate one-way ANOVA followed by Dunnett's test for each parameter. \#P $<0.05$, \#\#P $<0.01$ and \#\#\# $<0.001$ as compared to sham control, $* \mathrm{P}<0.05$, and $* * \mathrm{P}<0.01$, $* * * \mathrm{P}<0.001$ when compared to the OBX control, $\mathrm{n}=6 / \mathrm{group}$.

The significant $(\mathrm{P}<0.001)$ increase in the rearing score was observed in the OBX control rats as compared to sham control rats (130\% increase). Significant $(\mathrm{P}<0.001)$ reduction in rearing in the OBX rats was caused by imipramine $(20 \mathrm{mg} / \mathrm{kg})$, fluoxetine $(30 \mathrm{mg} / \mathrm{kg})$ and desipramine $(15 \mathrm{mg} / \mathrm{kg})$ treatment (reduction to $46.17,42.69$ and $52.24 \%$, respectively) as compared to the OBX control rats. $\operatorname{HECM}(50,100$ and $200 \mathrm{mg} / \mathrm{kg})$ treatment showed significant $(\mathrm{P}<0.05$ and $\mathrm{P}<0.001)$ reduction of rearing scores (reduction of 18.5, 31.22 and $36.96 \%$, respectively) as compared with the OBX control rats.

The grooming score of the OBX control rats was significantly ( $\mathrm{P}<0.001)$ more (increase by $34 \%$ ) than sham control rats. The treatment of imipramine, fluoxetine and desipramine reduced the grooming score significantly (reduction by $39.32,48$ and $49.32 \%$, respectively) as compared to the OBX control rats. HECM $(50,100$ and 200 $\mathrm{mg} / \mathrm{kg}$ ) treatment significantly reduced the grooming score by $22.68,28$, and $40.68 \%$, respectively as compared to the OBX group.

\section{Effect on physiological parameters in the OBX rats}

The effects on heart rate and body temperature in the OBX rats are presented in Table 2. Mean heart rate in sham control rats was 359.3 beats per min. Mean heart rate of the OBX control was significantly $(\mathrm{P}<0.001)$ reduced $(23.26 \%$ reduction) as compared to sham control group. Imipramine, fluoxetine or desipramine in the OBX 
rats caused significant increase in heart rate (increase of 58.85, 36.81 and 51\%, respectively) as compared to the OBX animals. HECM $(50,100$ or $200 \mathrm{mg} / \mathrm{kg}$ ) treatment caused dose-dependent and significant increase in heart rate (increase of 15.75, 18.51 and $23.38 \%$, respectively) as compared to the OBX rats.

The body temperature of the OBX control rats showed significant $(\mathrm{P}<0.001)$ reduction in the as compared to body temperature of sham control rats. Imipramine, fluoxetine and desipramine treatment caused significant $(\mathrm{P}<0.001)$ increase in body temperatures as compared to the OBX control rats by $5.04,6.34$ and $6.34 \%$, respectively. HECM treatment $(50,100$, and $200 \mathrm{mg} / \mathrm{kg}$ ) showed significant $(\mathrm{P}<0.001)$ increase in the body temperatures (by 5.85, 7.5 and $6.83 \%$, respectively) as compared with the OBX control.

\section{Effect on serum sodium concentration in the OBX rats}

Serum sodium concentration in sham control rats was $13.79 \mathrm{mEq} / \mathrm{L}$. OBX control rats showed significant $(\mathrm{p}<0.001)$ reductions in serum sodium concentration by $188.54 \%$ as compared to the OBX rats. Treatment with fluoxetine and HECM
$(50,100$ and $200 \mathrm{mg} / \mathrm{kg})$ significantly $(\mathrm{P}<0.001)$ reduced serum sodium concentration by 41.25 , $39.61, \quad 35.92$ and $63.56 \%$, respectively as compared to the OBX group. However, reduction showed by imipramine and desipramine in OBX rats was not significant as compared with the OBX control group.

\section{Effect during elevated plus maze test on the OBX rats}

The effects of treatments on number of open arm entries, number of closed arm entries and time spent in open arm during elevated plus maze test in the OBX rats is presented in Table 3 . Rats in the OBX control group showed significant $(\mathrm{P}<0.001)$ increase in mean open arm entries $(185 \%)$ as compared to sham control rats. Imipramine, fluoxetine and HECM (100 and $200 \mathrm{mg} / \mathrm{kg}$ ) treatments showed significant $(\mathrm{P}<0.001)$ reduction in the open arm entries $(67.5,68.83$, 55.55 and $57.14 \%$, respectively) as compared to OBX control rats. On the other hand, small increase showed by desipramine or HECM (50 $\mathrm{mg} / \mathrm{kg}$ ) treatment was not significant as compared to the OBX control rats.

Table 3 - Effect of treatments on elevated plus maze test in the OBX rats.

\begin{tabular}{lccc}
\hline Treatment & & Mean \pm SEM & \\
\cline { 2 - 4 } & Open arm entries (Number) & Closed arm entries (Number) & Time spent in open arm (sec) \\
\hline Sham control & $4.50 \pm 0.57$ & 5.160 .47 & $1.15 \pm 0.34$ \\
OBX control & $12.8 \pm 1.28^{\# \#}$ & $11.000 .63^{\# \# \#}$ & $3.94 \pm 0.20^{\# \# \#}$ \\
OBX+ Imipramine & $4.16 \pm 0.75^{* * *}$ & $5.000 .73^{* * *}$ & $1.71 \pm 0.40^{* * *}$ \\
OBX+ Fluoxetine & $4.00 \pm 0.36^{* * *}$ & $5.500 .80^{* * *}$ & $1.15 \pm 0.26^{* * *}$ \\
OBX+ Desipramine & $12.0 \pm 0.85$ & $4.831 .16^{* * *}$ & $4.40 \pm 0.35$ \\
OBX+ HECM (50) & $12.3 \pm 0.67$ & $5.000 .57^{* * *}$ & $2.46 \pm 0.09^{* *}$ \\
OBX+ HECM (100) & $5.83 \pm 0.60^{* * *}$ & $5.330 .33^{* * *}$ & $2.66 \pm 0.18^{*}$ \\
OBX+ HECM (200) & $5.50 \pm 0.34^{* * *}$ & $6.330 .42^{* * *}$ & $2.65 \pm 0.09^{* *}$ \\
\hline
\end{tabular}

The values are expressed as the Mean \pm SEM. The drug/vehicle treatments were administered once a day for 14 days. Figures in the bracket indicate dose in $\mathrm{mg} / \mathrm{kg}$, p.o. Data was analyzed by separate one-way ANOVA followed by Dunnett's test for each parameter. \#P $<0.05$, \#\#P $<0.01$, \#\# $<0.001$ as compared to sham control, $* \mathrm{P}<0.05$, **P $<0.01$ and $* * * \mathrm{P}<0.001$ when compared to the OBX control, $\mathrm{n}=6$ /group.

Rats in the OBX control group showed significant $(\mathrm{P}<0.001)$ increase in mean closed arm entries (by 53\%) as compared to sham control rats. Imipramine, fluoxetine and desipramine treatment showed significant $(\mathrm{P}<0.001)$ reduction in the closed arm entries $(54.55,50$ and $56.0 \%$ reduction, respectively) as compared to the OBX control rats. HECM (50, 100 and $200 \mathrm{mg} / \mathrm{kg}$ ) treatment significantly $(\mathrm{P}<0.001)$ reduction in number of closed arm entries (by 54.55, 61.55 and $42.46 \%$, respectively) as compared with the OBX control rats.

OBX control rats showed significant $(\mathrm{P}<0.001)$ increase in the time spent in open arm (70.89\%) as compared to sham control rats. Imipramine and fluoxetine treatment showed significant $(\mathrm{P}<$ 0.001 ) reduction in the time spent in open arm (43.54 and $70.89 \%$ reduction, respectively) as compared with the OBX control rats. Desipramine treatment showed significant increase $(\mathrm{P}<0.05)$ in the time spent in open arm (11.39\% increases) as 
compared to the OBX control rats. HECM (50, 100 and $200 \mathrm{mg} / \mathrm{kg}$ ) treatment showed significant reduction in the time spent in open arm (37.4, 32.66 and $32.92 \%$ reduction, respectively) as compared to OBX control rats.

\section{DISCUSSION}

OBX induced rats is well validated animal model of stress-induced depression (Leonard 1984; Kelly et al. 1997). OBX produces hyper-emotional behaviour in the rats and is proven method for evaluating specificity in the mechanism of antidepressant activity (Lumia et al. 1992; Bourin et al. 2001), especially after chronic administration (Jancsar and Leonard 1984). In the past, alterations in feeding patterns and circadian rhythms have been reported in bulbectomized rats (McElroy et al. 2004; McElroy et al. 2005). OBX-induced depression involves deficits in appetite-motivated behaviors, resulting increase in eating frequency (Meguid et al. 1997) and food intake (Kelly et al. 1996). The increase in 24-h food intake shown by OBX rats in this study was in line with earlier results of OBX (McElroy et al. 2004; McElroy et al. 2005). In the present study, HECM treatment showed protective OBX rats from the hyperphagia (increased food intake), which resembled to the effects of standard antidepressants such as fluoxetine (Slotkin et al. 2000), imipramine (Muscat et al. 1990), desipramine (Nobrega and Coscina 1987), and thus confirming antidepressant potential of HECM in the OBX induced rats.

These effects of HECM can be mediated by numerous mechanisms. Serotonin (5-HT) is known to act as central inhibitor of food intake in mammals. Administration of 5-HT or its analogue reduced food intake and stimulated energy consumption in both human and rats (Vickers et al. 2001; Choi et al. 2002). OBX animals showed a lower rate of 5-HT synthesis under basal conditions. However, the capacity of the system to synthesize 5-HT was not affected (van der Stelt et al. 2005). Depletion of serotonin in the depression is the main cause of hyperphagia (Breisch et al. 1976). It has been recently demonstrated that reactive oxygen species (ROS) in the hypothalamus are a crucial integrative target for the regulation of food intake (Fang et al. 2013). Alterations in the NPY levels can be another potential mechanism for HECM. OBX increases
NPY Y2 receptor mRNA levels in the medial nucleus of the amygdala in rats (Primeaux et al. 2007).

OBX is also associated with decrease in rat's defensive behavior after exposure to the novel environment as reported earlier (Katz et al. 1981; Primeaux and Holmes 1999) Antidepressants are known to increase the adaptive response in novel stressful environment and decrease the ability of chronically stressed rats to respond actively to stress (Katz et al. 1981). In the present study, HECM was shown to normalize stress related parameters in open field and elevated plus maze test suggesting the reduction in defensive behavior of OBX rats.

Novelty exposure transiently increases extracellular glutamate levels in the striatum of the OBX rats, but not in sham-operated rats. This increase occurs coincidentally with an increase in behavioral hyperactivity of OBX rats exposed to novelty stress, suggesting that novelty exposure induces activation of the striatal glutamatergic system in OBX rats and may consequently cause behavioral hyperactivity (Ho et al. 2000). The protective effects of HECM against OBX hyperactivity can be attributed to release of striatal glutamate release. However, more investigations would be needed to confirm glumatamineric hypothesis in mechanism of HECM.

Increased exploratory behavior and glutamate release in the nucleus accumbens has been shown to occur in rats $10 \mathrm{~min}$ after novelty exposure such as open filed test. Chronic antidepressant is known to enhance habituation of OBX animals only under more stressful or aversive conditions and do so in a manner temporally distinct from anxiolytic treatment (Mar et al. 2002). In the present study, HECM showed dose dependent normality of exploratory behavior in OBX rats after exposure to novelty stress during open field test.

The OBX rats are characterized by low thermal set points (Kelly et al. 1996). Changes in body temperature and heart rate emerged quickly after OBX surgery with decreased body temperature levels and decreased daily heart rate levels, indicating the loss of vagal control (Vinkers et al. 2009). HECM was shown to protect the rats from OBX induced changes on heart rate and body temperature, suggesting the restoration of vagal control by HECM. Lower resting heart rate was observed in the OBX rats, as well as when placed in a novel environment, suggesting altered noradrenergic function in the amygdala region of 
brain (van Riezen and Leonard 1990). OBX is associated with the hyperactivity of hypothalamicpituitary-adrenal axis (HPA) axis (Berton and Nestler 2006). Depression associated with chronic stressful conditions is associated with over expression of corticotropin-releasing factor (CRF), which is responsible for further elevation of blood cortisol and subsequently increased sodium concentration (Hauger et al. 2009). The normalization of body temperature heart rate and sodium concentration shown by HECM in the present study indicated the role of HPA axis in the anti-depressant mechanism of HECM.

\section{CONCLUSIONS}

HECM showed restorative effects on the behavioral, physiological and stress related parameters in the OBX induced rats and could be considered as potential option for the development of agent against stress-induced depression.

\section{ACKNOWLEDGMENT}

The authors would like acknowledge Dr. B. S. Kuchekar, Principal, Maharashtra Institute of Pharmacy, PuneUniversity, Pune, India for providing necessary facilities to carry out the study.

\section{REFERENCES}

Almazari I, Park JM, Park SA, Suh JY, Na HK, Cha YN, et al. Guggulsterone induces heme oxygenase-1 expression through activation of $\mathrm{Nrf} 2$ in human mammary epithelial cells: PTEN as a putative target. Carcinogenesis. 2012; 33(2): 368-376.

Bellamkonda R, Rasineni K, Singareddy SR, Kasetti RB, Pasurla R, Chippada AR, et al. Antihyperglycemic and antioxidant activities of alcoholic extract of Commiphora mukul gum resin in streptozotocin induced diabetic rats. Pathophysiology. 2011; 18(4): 255-261.

Berton O, Nestler EJ. New approaches to antidepressant drug discovery: beyond monoamines. Nat Rev Neurosci. 2006; 7(2): 137-151.

Bourin M, Fiocco A, Clenet F. How valuable are animal models in defining antidepressant activity? Hum Psychopharmacol Clin Exp. 2001; 16(1): 9-21.

Breisch ST, Zemlan FP, Hoebel BG. Hyperphagia and obesity following serotonin depletion by intraventricular p-chlorophenylalanine. Science. 1976; 192(4237): 382385 .
Choi S, Jonak EM, Simpson L, Patil V, Fernstrom JD. Intermittent, chronic fenfluramine administration to rats repeatedly suppresses food intake despite substantial brain serotonin reductions. Brain Res. 2002; 928(1-2): 30-39.

Cole DA, Cho SJ, Martin NC, Youngstrom EA, March JS, Findling RL, et al. Are increased weight and appetite useful indicators of depression in children and adolescents? J Abnorm Psychol. 2012; 121(4): 838-851.

Fang XL, Shu G, Yu JJ, Wang LN, Yang J, Zeng QJ, et al. The anorexigenic effect of serotonin is mediated by the generation of NADPH oxidase-dependent ROS. PLoS One. 2013; 8(1): e53142.

Freitas AE, Machado DG, Budni J, Neis VB, Balen GO, Lopes MW, et al. Antidepressant-like action of the bark ethanolic extract from Tabebuia avellanedae in the olfactory bulbectomized mice. J Ethnopharmacol. 2013; 145(3): 737-745.

Hadipour JM, Khakpour S, Farnaghi S. The study of Commiphora Mukul resin extract effect on increasing physical stamina in male rat. Med Sci J Islamic Azad Univ. 2008; 18(3): 149-153.

Hauger RL, Risbrough V, Oakley RH, Olivares-Reyes JA, Dautzenberg FM. Role of CRF receptor signaling in stress vulnerability, anxiety, and depression. Ann NY Acad Sci. 2009; 1179120-143.

Hirsch JK, Webb JR, Jeglic EL. Forgiveness, depression, and suicidal behavior among a diverse sample of college students. J Clin Psychol. 2011; 67(9): 896-906.

Ho YJ, Chang YC, Liu TM, Tai MY, Wong CS, Tsai YF. Striatal glutamate release during novelty exposureinduced hyperactivity in olfactory bulbectomized rats. Neurosci Lett. 2000; 287(2): 117-120.

Jancsar SM, Leonard BE. Changes in neurotransmitter metabolism following olfactory bulbectomy in the rat. Prog Neuropsychopharmacol Biol Psychiatry. 1984; 8(2): 263-269.

Kalshetty P, Aswar U, Mohan V, Bodhankar SL, Arulmozhi S, Thakurdesai PA. Antidepressant effects of standardized extract of Centella asiatica L in olfactory bulbectomy model. Biomedicine \& Aging Pathology. 2012; 2(2): 48-53.

Katz RJ, Roth KA, Carroll BJ. Acute and chronic stress effects on open field activity in the rat: implications for a model of depression. Neurosci Biobehav Rev. 1981; 5(2): 247-251.

Kaur G, Kulkarni SK. Involvement of normal physiological mechanisms in mediation of satiety by polyherbal antiobesity preparation, OB-200G, in female mice. Methods Find Exp Clin Pharmacol. 2003; 25(1): 33-39.

Kelly J, Norman T, O'halloran A, Leonard B. Home cage and open-field locomotor activity responses in singly housed olfactory bulbectomised rats. Med Sci Res. 1996; 24(5): 335-337.

Kelly J, Wrynn A, Leonard B. The olfactory bulbectomized rat as a model of depression: an update. Pharmacol Ther. 1997; 74(3): 299-316. 
Kelsch W, Sim S, Lois C. Increasing heterogeneity in the organization of synaptic inputs of mature olfactory bulb neurons generated in newborn rats. J Comp Neurol. 2012; 520(6): 1327-1338.

Khan S, Dwivedi C, Parmar V, Srinivasan KK, Shirwaikar A. Methanol extract of dried exudate of Commiphora mukul prevents bone resorption in ovariectomized rats. Pharm Biol. 2012; 50(10): 1330-1336.

Leonard BE. The olfactory bulbectomized rat as a model of depression. Pol J Pharmacol Pharm. 1984; 36(5): 561-569.

Leonard BE, Tuite M. Anatomical, physiological, and behavioral aspects of olfactory bulbectomy in the rat. Int Rev Neurobiol. 1981; 22251-286.

Lumia AR, Teicher MH, Salchli F, Ayers E, Possidente B. Olfactory bulbectomy as a model for agitated hyposerotonergic depression. Brain Res. 1992; 587(2): 181-185.

Mar A, Spreekmeester E, Rochford J. Fluoxetine-induced increases in open-field habituation in the olfactory bulbectomized rat depend on test aversiveness but not on anxiety. Pharmacol Biochem Behav. 2002; 73(3): 703-712.

McElroy SL, Kotwal R, Keck PE, Jr., Akiskal HS. Comorbidity of bipolar and eating disorders: distinct or related disorders with shared dysregulations? J Affect Disord. 2005; 86(2-3): 107-127.

McElroy SL, Kotwal R, Malhotra S, Nelson EB, Keck PE, Nemeroff CB. Are mood disorders and obesity related? A review for the mental health professional. J Clin Psychiatry. 2004; 65(5): 634-651.

Meguid MM, Koseki M, Yang ZJ, Gleason JR, Laviano A. Acute adaptive changes in food intake pattern following olfactory ablation in rats. Neuroreport. 1997; 8(6): 1439-1444.

Moreau JL. Simulating the anhedonia symptom of depression in animals. Dialogues Clin Neurosci. 2002; 4(4): 351-360.

Morilak DA, Frazer A. Antidepressants and brain monoaminergic systems: a dimensional approach to understanding their behavioural effects in depression and anxiety disorders. Int J Neuropsychopharmacol. 2004; 7(2): 193-218.

Muscat R, Sampson D, Willner P. Dopaminergic mechanism of imipramine action in an animal model of depression. Biol Psychiatry. 1990; 28(3): 223-230.

Nobrega JN, Coscina DV. Effects of chronic amitriptyline and desipramine on food intake and body weight in rats. Pharmacol Biochem Behav. 1987; 27(1): 105-112.

Pal P, Kanaujiya JK, Lochab S, Tripathi SB, Sanyal S, Behre $\mathrm{G}$, et al. Proteomic analysis of rosiglitazone and guggulsterone treated 3T3-L1 preadipocytes. Mol Cell Biochem. 2013; 376(1-2): 81-93.

Primeaux SD, Barnes MJ, Bray GA. Olfactory bulbectomy increases food intake and hypothalamic neuropeptide $\mathrm{Y}$ in obesity-prone but not obesity-resistant rats. Behav Brain Res. 2007; 180(2): 190-196.

Primeaux SD, Holmes PV. Role of aversively motivated behavior in the olfactory bulbectomy syndrome. Physiol Behav. 1999; 67(1): 41-47.
Ramesh B, Saralakumari D. Antihyperglycemic, hypolipidemic and antioxidant activities of ethanolic extract of Commiphora mukul gum resin in fructose-fed male Wistar rats. J Physiol Biochem. 2012; 68(4): 573 582.

Saitoh A, Yamaguchi K, Tatsumi Y, Murasawa H, Nakatani A, Hirose N, et al. Effects of milnacipran and fluvoxamine on hyperemotional behaviors and the loss of tryptophan hydroxylase-positive cells in olfactory bulbectomized rats. Psychopharmacol (Berl). 2007; 191(4): 857-865.

Scott RO. The determination of sodium and potassium in blood serum and urine by means of the flame photometer. Spectrochim Acta. 1951; 4(4): 314.

Shah R, Gulati V, Palombo EA. Pharmacological properties of guggulsterones, the major active components of gum guggul. Phytother Res. 2012; 26(11): 1594-1605.

Shen T, Zhang L, Wang Y-Y, Fan P-H, Wang X-N, Lin Z$M$, et al. Steroids from Commiphora mukul display antiproliferative effect against human prostate cancer PC3 cells via induction of apoptosis. Bioorg Med Chem Lett. 2012; 22(14): 4801-4806.

Siddiqui Z. Guggul: an excellent herbal panacea. Asian $J$ Pharma Health Sci. 2011; 135-139.

Slotkin TA, Seidler FJ, Ritchie JC. Regional differences in brain monoamine oxidase subtypes in an animal model of geriatric depression: effects of olfactory bulbectomy in young versus aged rats. Brain Res. 2000; 882(1-2): 149-154.

Srivastava M, Kapoor N. Guggulsterone induced changes in the levels of biogenic monoamines and dopamine $\beta$ hydroxylase activity of rat tissues. J Biosci. 1986; 10(1): 15-19.

van der Stelt HM, Breuer ME, Olivier B, Westenberg HG. Permanent deficits in serotonergic functioning of olfactory bulbectomized rats: an in vivo microdialysis study. Biol Psychiatry. 2005; 57(9): 1061-1067.

van Riezen H, Leonard BE. Effects of psychotropic drugs on the behavior and neurochemistry of olfactory bulbectomized rats. Pharmacol Ther. 1990; 47(1): 2134.

Vickers SP, Dourish CT, Kennett GA. Evidence that hypophagia induced by $\mathrm{d}$-fenfluramine and $\mathrm{d}$ norfenfluramine in the rat is mediated by 5-HT2C receptors. Neuropharmacology. 2001; 41(2): 200-209.

Vinkers $\mathrm{CH}$, Breuer ME, Westphal KG, Korte SM, Oosting RS, Olivier B, et al. Olfactory bulbectomy induces rapid and stable changes in basal and stressinduced locomotor activity, heart rate and body temperature responses in the home cage. Neuroscience. 2009; 159(1): 39-46.

Received: December 24, 2013; Accepted: September 30, 2014. 